\title{
Use of cystourethroscopy to remove an indwelling double-J ureteral stent 6 years following simultaneous radical sigmoid colon cancer and partial bladder resection: A case report
}

\author{
YAN GU, JING ZHANG and GUOZENG WANG \\ Department of Urology, Pudong New Area Gongli Hospital, Shanghai 200135, P.R. China
}

Received January 21, 2015; Accepted March 1, 2016

DOI: $10.3892 /$ etm.2016.3192

\begin{abstract}
Ureteral stents are widely used to ensure good urinary drainage and to relieve obstruction, pain and infection during urologic procedures. However, long-term indwelling ureteral stents can cause various complications, such as encrustation, hematuria and infection. Here, the case of an 88-year-old man who had undergone simultaneous radical resection of sigmoid colon cancer and partial resection of the bladder 6 years prior is presented. The patient complained of urinary frequency and urgency, dysuria and intermittent fever. A kidney ureter bladder X-ray examination revealed the presence of an entire coiled double-J stent with calculi from the kidney to the bladder. A computed tomography scan revealed mild hydronephrosis of the left kidney and one $\mathrm{J}$ end of the stent in the bladder. The stent was removed successfully by cystourethroscopy and holmium laser lithotripsy. This report describes the clinical experience of the removal of a long-term stent by endoscopic manipulation.
\end{abstract}

\section{Introduction}

Ureteral stents are frequently used equipment in urology, and are basic but specially designed hollow tubes that are placed in the ureter. Stents with different diameters or gauges are used in adult patients to fit different sized ureters. Three different types of stents, including artificial polymeric stents, ureteral stents, metallic ureteral stents and degradable ureteral stents, are widely used in urologic procedures $(1,2)$. Ureteral stents, particularly double-J (D-J) stents, are widely used in endourologic procedures to relieve obstruction, pain and infection during urologic procedures (3). These stents should be removed within a safe time frame by endourologic or other auxiliary techniques (4). Keeping a stent in the ureter for a long period of

Correspondence to: Dr Guozeng Wang, Department of Urology, Pudong New Area Gongli Hospital, 219 Miaopu Road, Shanghai 200135, P.R. China

E-mail: jiao602@126.com

Key words: ureteral stent, complications, cystourethroscopy, lithotripsy time carries a risk of microorganisms developing a biofilm on the stent surface. Serious complications may arise if a stent is not removed within 3 months, such as encrustation, hematuria and infection (5). Recently, multiple endourological approaches and open surgery have been developed to remove the stents in patients with stent-related complications. An endourological procedure is widely accepted for removing ureteral stents, which is more efficient with less wound complications and shorter recovery times than open surgery $(6,7)$. The present study reports a rare case of a patient with a coiled D-J stent which was not removed for 6 years, which resulted in the development of encrustation and was extracted successfully by cystourethroscopy with holmium laser lithotripsy.

\section{Case report}

An 88-year-old man was admitted to the Department of Urology, Pudong New Area Gongli Hospital (Shanghai, China) on 6th May 2006 with complaints of urinary frequency and urgency, dysuria and intermittent fever (maximum temperature, $38.3^{\circ} \mathrm{C}$ ) lasting 1 week. Approximately 6 years prior, the patient had undergone simultaneous radical resection of sigmoid colon cancer and partial resection of the bladder. At that time, a D-J stent (Cook Ireland, Ltd., Limerick, Ireland) was inserted to prevent transient urinary tract obstruction and postoperative flank pain from ureteral edema and blood clots. Informed consent was obtained from the patient to report this case. A follow-up appointment had been arranged, which the patient did not attend. The present study was approved by the ethics committee of Pudong New Area Gongli Hospital.

Physical examination at admission was unremarkable except for a previous surgical scar. Hematological and biochemical investigations (8), including a blood, urinary and renal function test, were also unremarkable, with a white blood cell count of $7.4 \times 10^{9} / 1$ (normal, $3.5-9.5 \times 10^{9}$ cells $/ 1$ ), $72.3 \%$ neutrophils (normal, 50-70\%) and a serum creatinine level of $147 \mu \mathrm{mol} / 1$ (normal, $41-144 \mu \mathrm{mol} / \mathrm{l}$ ). Urinalysis (UF-100 automated urinalysis analyzer; Koehler Instrument Company, Inc., New York, NY USA) (9) revealed pyuria (105 white blood cells/high-powered field). Urine cultures were positive for Enterococcus faecalis (Group D Streptococcus system), Escherichia coli and Aeromonas hydrophila, which were sensitive to penicillin (Suzhou Erye Pharmaceutical Co., Ltd., Suzhou, China) and kanamycin (Zhejiang Shapuaisi 


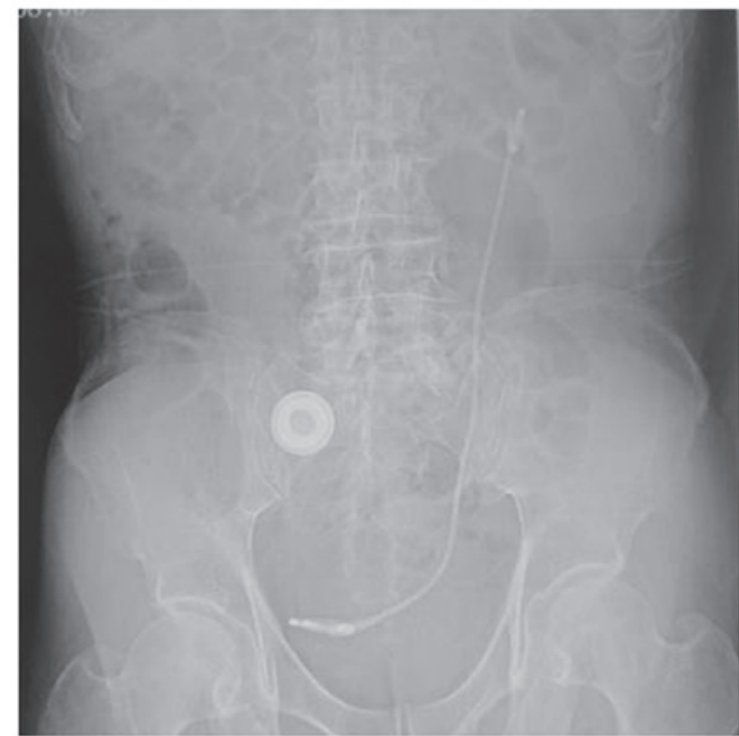

Figure 1. Kidney, ureter and bladder X-ray image showing a double-J ureteric stent from the kidney to the bladder.
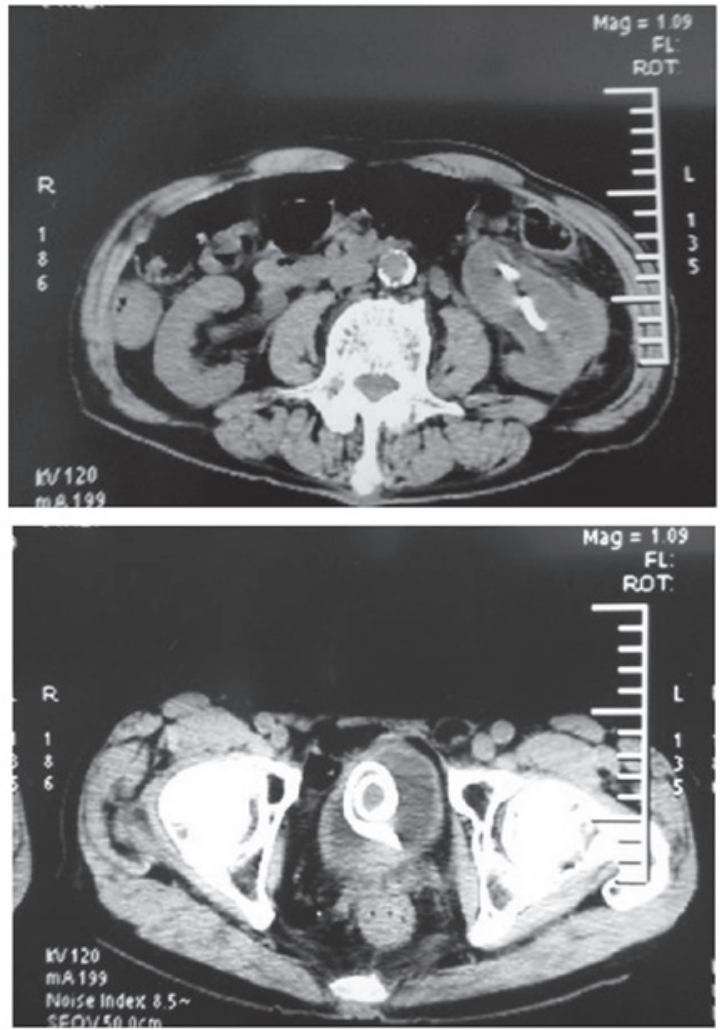

Figure 2. Computed tomography urography scans showing left hydronephrosis and a calcified double-J stent at the vesical coil within the bladder.

Pharmaceutical Co., Ltd., Zhejiang, China). Kidney ureter bladder (KUB) X-ray examination revealed the presence of an entire coiled D-J stent from the kidney to the bladder (Fig. 1). Computed tomography (CT) urography scans demonstrated left hydronephrosis and an encrusted D-J stent with calculi on the vesical coil (Fig. 2).

Following treatment of the urinary tract infection (UTI) with penicillin and kanamycin, cystoscopy (22 FSTORZ;

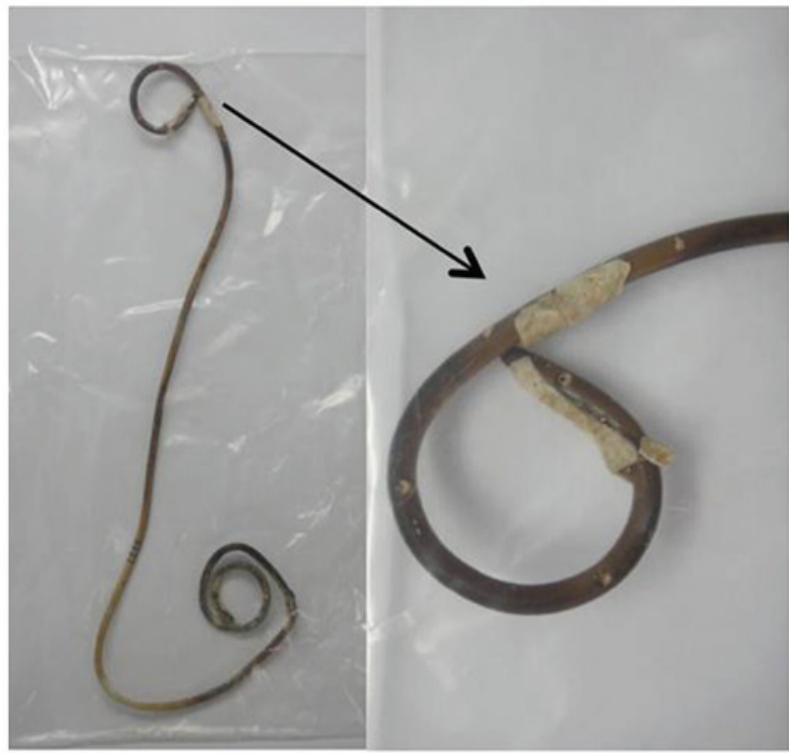

Figure 3. Entire encrusted double-J stent following surgical removal.

Karl-Storz GmbH \& Co., KG, Tittlingen, Germany) was performed with holmium laser lithotripsy (Cohernt Inc., Santa Clara, CA, USA) under spinal anesthesia to remove the D-J stent. However, this procedure failed as the stent was curled at one end and coated with a calcified encrustation in the left ureter. Under an irrigation pressure of $40 \mathrm{~cm} \mathrm{H}_{2} \mathrm{O}$, an 8/9.5F STORZ ureteroscope (Karl-Storz GmbH \& Co., KG) was placed into the bladder. Encrusted stones surrounding the D-J stent, in particular in the upper coil, were disintegrated with $2 \mathrm{~J} / 8 \mathrm{HZ}$ holmium laser lithotripsy. The D-J stent was removed into the bladder. An intact D-J ureteral stent, which was coated with yellow calculus, was withdrawn from the bladder using a grasper under cystoscopy (Fig. 3). The bladder was washed with saline to clear the stones completely. The whole procedure for D-J stent removal took $45 \mathrm{~min}$.

Postoperatively, the antibiotic regimen was changed to vancomycin (Vianex S.A., Athens, Greece), on the basis of the sensitivity of the bacterial culture of the stones (Staphylococcus haemolyticus). One week later, the patient remained in good health and free of infection. The patient was discharged 14 days after admission to the hospital (20th May 2006). The postoperative period was uneventful, and the patient developed no complications by the end of the 1-month follow-up period.

\section{Discussion}

The D-J ureteral stent is one of the most basic and valuable tools used to prevent obstruction of the urinary tract and to maintain its patency following endourological procedures and urologic open surgery (9). The D-J stent enables direct drainage of the upper urinary tract into the bladder without the need for an external diversion (10). Complications of short-term stent placement (3-9 weeks) include flank pain and irrigative voiding symptoms, hematuria, dysuria, frequency, and suprapubic pain (11). Complications may also occur following the long-term placement of stents in patients who do not attend the follow-up. These delayed complications 
include stenturia and hydronephrosis, encrustation, blockage, impaction, migration, knotting, fracture and spontaneous fragmentation of the stent $(12,13)$. As the use of indwelling ureteral stents has increased, stent-associated infections have become more frequent (14). Bacterial stent colonization by multiple pathogens starts at 2 weeks and is followed by UTI (15). Enterococcus species and E. coli are the main causative pathogens and can spread rapidly (16).

Stent encrustation is common in the use of long-term ureteral stents. Ureteral stents that are left in place for $>6$ months are commonly encrusted (17-19). In the present case, the stent was in situ for 6 years, and the patient developed stone formation, encrustation and UTI. Numerous previous studies have reported various multimodal endourologic approaches to remove encrusted and retained stents, including extracorporal shockware lithotripsy, ureteroscopy with or without intracorporal retrieval, and percutaneous nephrolithotmy (20-22). For long-term D-J stents with severe encrustation, ureteroscopy in combination with holmium laser lithotripsy could represent an alternative, minimally invasive treatment option (4). In the present study, cystourethroscopy with holmium laser lithotripsy was used to manage the potentially life-threatening complications by extracting the stent.

When a D-J stent must be used, the patient should be educated about the need for its timely removal, and provided with detailed information about stent removal. Contact information for the patient should be recorded, to avoid unnecessary patient morbidity and potential legal problems. Close patient monitoring could reduce the possibility of leaving a stent in situ. The current study suggested that cystourethroscopy with holmium laser lithotripsy may be an effective and less invasive method for removing encrusted D-J stents that have been in place for a long time.

\section{References}

1. Elsamra SE, Leavitt DA, Motato HA, Friedlander JI, Siev M, Keheila M, Hoenig DM, Smith AD and Okeke Z: Stenting for malignant ureteral obstruction: Tandem, metal or metal-mesh stents. Int J Urol 22: 629-636, 2015.

2. Fiuk J, Bao Y, Calleary JG, Schwartz BF and Denstedt JD: The use of internal stents in chronic ureteral obstruction. J Urol 193: 1092-1100, 2015

3. Haleblian G, Kijvikai K, de la Rosette J and Preminger G: Ureteral stenting and urinary stone management: A systematic review. J Urol 179: 424-430, 2008.

4. Xu C, Tang H, Gao X, Gao X, Yang B and Sun Y: Management of forgotten ureteral stents with holmium laser. Lasers Med Sci 24: 140-143, 2009
5. Olvera-Posada D, Suárez-Santos M, Castillejos-Molina R, Gabilondo-Navarro F and Méndez-Probst CE: Validation of the Spanish version of Ureteral Stent Symptom Questionnaire: Prevalence of symptoms in a tertiary care center in Mexico. J Endourol 28: 377-382, 2014.

6. Murthy KV, Reddy SJ and Prasad DV: Endourological management of forgotten encrusted ureteral stents. Int Braz J Urol 36: 420-429, 2010.

7. Bostanci Y, Ozden E, Atac F, Yakupoglu YK, Yilmaz AF and Sarikaya S: Single session removal of forgotten encrusted ureteral stents: Combined endourological approach. Urol Res 40: 523-529, 2012.

8. Hunt L, Gupta-Wright A, Simms V, Tamba F, Knott V, Tamba K, Heisenberg-Mansaray S, Tamba E, Sheriff A, Conteh S, et al: Clinical presentation, biochemical, and haematological parameters and their association with outcome in patients with Ebola virus disease: an observational cohort study. Lancet Infect Dis 15: 1292-1299, 2015.

9. Lumma PP, Schneider P, Strauss A, Plothe KD, Thelen P, Ringert RH and Loertzer H: Impact of ureteral stenting prior to ureterorenoscopy on stone-free rates and complications. World J Urol 31: 855-859, 2013.

10. Matani YS, Al-Ghazo MA, Al-azab RS, Bani-hani O and Rabadi DK: Emergency double-J stent insertion following uncomplicated Ureteroscopy: Risk-factor analysis and recommendations. Int Braz J Urol 39: 203-208, 2013.

11. Ringel A, Richter S, Shalev M and Nissenkorn I: Late complications of ureteral stents. Eur Urol 38: 41-44, 2000.

12. Bhuiyan ZH, Bhuiyan NI, Khan SA, Tawhid MH and Islam MF: Forgotten urological stent. Mymensingh Med J 20: 632-639, 2011.

13. Wani B, Upadhey R, Rathod V and Bhole A: Forgotten long-term indwelling doubl' 'J/ stent. Saudi J Kidney Dis Transpl 23: 1043-1045, 2012.

14. Pengfei S, Yutao L, Jie Y, Wuran W, Yi D, Hao Z and Jia W: The results of ureteral stenting after ureteroscopic lithotripsy for ureteral calculi: A systematic review and meta-analysis. J Urol 186: 1904-1909, 2011.

15. Aydin HR, Irkilata L, Aydin M, Gorgun S, Demirel HC, Adanur S, Keles M, Atilla A and Atilla MK: Incidence of bacterial colonisation after indwelling of double-J ureteral stent. Arch Ital Urol Androl 87: 291-294, 2016.

16. Soyupek S, Oksay T and Koşar A: Fragmentation of a forgotten double $\mathrm{J}$ stent and excreted with urine: Case report. Int Urol Nephrol 35: 91-92, 2003.

17. Tsai CC, Shen JT, Huang SP, Chang SF, Tsai LJ, Wu WJ and Huang $\mathrm{CH}$ : Use of a holmium laser to treat a forgotten double-J stent with whole stent encrustations: A case report. Kaohsiung J Med Sci 25: 567-571, 2009.

18. Ignjatovic I and Stojkovic I: Trapping of the double-J stent in the urinary tract eight years after extracorporeal shock wave lithotripsy. Int Urol Nephrol 32: 29-31, 2000.

19. Singh V, Srinivastava A, Kapoor R and Kumar A: Can the complicated forgotten indwelling ureteric stents be lethal? Int Urol Nephrol 37: 541-546, 2005.

20. Borboroglu PG and Kane CJ: Current management of severely encrusted ureteral stents with a large associated stone burden. J Urol 164: 648-650, 2000.

21. Bultitude MF, Tiptaft RC, Glass JM and Dasgupta P: Management of encrusted ureteral stents impacted in upper tract. Urology 62: 622-626, 2003.

22. Lam JS and Gupta M: Tips and tricks for the management of retained ureteral stents. J Endourol 16: 733-741, 2002. 